\title{
Article \\ An Assembly-Oriented Design Framework for Additive Manufacturing
}

\author{
Germain Sossou, Frédéric Demoly *D, Samuel Gomes and Ghislain Montavon
}

check for updates

Citation: Sossou, G.; Demoly, F.;

Gomes, S.; Montavon, G. An

Assembly-Oriented Design

Framework for Additive

Manufacturing. Designs 2022, 6, 20

https://doi.org/10.3390/

designs 6010020

Academic Editor: Obeidi Muhannad

Received: 21 January 2022

Accepted: 17 February 2022

Published: 18 February 2022

Publisher's Note: MDPI stays neutral with regard to jurisdictional claims in published maps and institutional affiliations.

Copyright: (C) 2022 by the authors. Licensee MDPI, Basel, Switzerland. This article is an open access article distributed under the terms and conditions of the Creative Commons Attribution (CC BY) license (https:// creativecommons.org/licenses/by/ $4.0 /)$.
ICB UMR 6303 CNRS, University Bourgogne Franche-Comté, UTBM, 90010 Belfort, France; germain.sossou@outlook.fr (G.S.); samuel.gomes@utbm.fr (S.G.); ghislain.montavon@utbm.fr (G.M.) * Correspondence: frederic.demoly@utbm.fr

\begin{abstract}
The shape complexity capability of additive manufacturing (AM) is currently the main thrust of the design for AM (DFAM) research. In order to aid designers embracing that complexityfor-free characteristics of AM, many design approaches have been put forth. However, AM does not only benefit parts' designs: its capability can be harnessed at assembly level to design performant and innovative products. Most of the few contributions on the topic are concerned with part consolidation of existing assemblies, but other advantages such as assembly-free mechanisms, multi-material components, or even component embedding can also improve product design complexity. This paper aims to put forth a thorough DFAM framework for new product development (made of multiple parts) and which consider all the assembly-related characteristics of AM. It considers what can be called AM-based architecture minimization, which includes, among others, part consolidation and assembly-free mechanisms as well. Within context of an 'AM-factory', in which the most appropriate machine(s) is/are selected for easing a whole assembly manufacturing before the detailed geometric definition is committed. For the sake of completeness, a methodology based on functional flows has also been investigated for the parts' design. A gripper as case study has been introduced to illustrate the framework.
\end{abstract}

Keywords: design for additive manufacturing; additive manufacturing; assembly; part consolidation; assembly-free mechanisms

\section{Introduction}

Originally considered as a physical prototyping process, additive manufacturing (AM) is now being investigated and used for end-of-use products. Such endeavor can be traced to the expansion of both the techniques following the principle of AM and the materials processed by them (as shown in Table 1). As such, a new paradigm shift is taking place in the way we manufacture goods. For instance, while conventional (i.e., subtractive or formative) processes would require a product to be manufactured sequentially in many simple shape parts and then to be assembled, the layer-by-layer manufacturing peculiar to AM allows single step manufacturing of products featuring complex shapes (difficult or impossible to manufacture with conventional processes).

However, for this paradigm shift to be complete, it is needed to undertake significant efforts from the early design stages and do over current models, methods, and tools accordingly, and/or promote new ones. In a way similar to how research efforts have been targeted at design for X [1] - design for manufacture (DFM) or design for assembly (DFA) [2] - to aid designers in delivering solutions that are easily manufacturable and ready for a seamless assembly, research has to be carried out to design in embracing the full potentials of AM. As such, a new trend in the design theory and methodology realm has emerged under the umbrella term of design for additive manufacturing (DFAM) [3,4]. 
Table 1. Additive manufacturing processes classification.

\begin{tabular}{|c|c|c|c|}
\hline Family Process & Description & Typical Processed Material & Typical Technique \\
\hline Material extrusion & $\begin{array}{l}\text { A material is semi-solid state is } \\
\text { extruded through a nozzle/needle } \\
\text { and is cured. }\end{array}$ & $\begin{array}{l}\text { Polymers, ceramics, metals, } \\
\text { wood }\end{array}$ & $\begin{array}{l}\text { Fused Filament Fabrication (FFF), } \\
\text { Robocasting (Direct Ink Writing), }\end{array}$ \\
\hline Powder bed fusion & $\begin{array}{l}\text { A thermal source selectively fuses } \\
\text { layers of powder. }\end{array}$ & Polymers, ceramics, metals & $\begin{array}{l}\text { Selective Laser Sintering (SLS), } \\
\text { Selective Laser Melting (SLM) }\end{array}$ \\
\hline Photopolymerization & $\begin{array}{l}\text { Layers of photopolymers are } \\
\text { selectively cured upon exposure to a } \\
\text { radiation. }\end{array}$ & Photocurable polymers & Sterelithography (SLA) \\
\hline Directed energy deposition & $\begin{array}{l}\text { A focused high power laser beam } \\
\text { melts a material powder as it is being } \\
\text { deposited. }\end{array}$ & Metals & $\begin{array}{l}\text { Laser Engineered Net Shaping } \\
\text { (LENS), Direct Metal Deposition } \\
\text { (DMD), 3D laser cladding }\end{array}$ \\
\hline Sheet lamination & $\begin{array}{l}\text { Material sheets are bonded; each sheet } \\
\text { (representing a cross section of the } \\
\text { CAD model) is selectively cut with an } \\
\text { energy source. }\end{array}$ & Papers, metals, polymers & $\begin{array}{l}\text { Laminated Object Manufacturing } \\
\text { (LOM), Ultrasonic Consolidation } \\
\text { (UC) }\end{array}$ \\
\hline Material jetting & $\begin{array}{l}\text { Droplets of a material (or a mix of two } \\
\text { materials) are selectively deposited in } \\
\text { thin layers from a print head, and } \\
\text { cured either by a source of energy or } \\
\text { by environmental conditions. }\end{array}$ & Polymers, wax & $\begin{array}{l}\text { Multi-Jet Modeling } \\
\text { (Drop-On-Demand), PolyJet }\end{array}$ \\
\hline Binder jetting & $\begin{array}{l}\text { A binder is selectively deposited, from } \\
\text { a printhead, onto a powder bed, } \\
\text { forming a section of the CAD model. }\end{array}$ & $\begin{array}{l}\text { Plastics, metals, composites, } \\
\text { ceramics, polymers }\end{array}$ & 3D printing \\
\hline
\end{tabular}

AM is mainly praised for its capability to manufacture intricate shapes or interlocking features that are unfeasible with conventional processes. This is reflected in the vast majority of work in the DFAM-related literature. Most of the current contributions to the field seem to be mainly dedicated to parts' design where the goals are basically twofold: (i) providing tools and methodologies for embracing the shape complexity capability of AM in order to improve performance, and (ii) constraining the design process by considering AM specific manufacturing constraints. As such, these contributions are essential for a better adoption of AM by designers and engineers [5,6]. However, as components rarely work by themselves and are usually part of a whole assembly, the design freedom allowed by AM should be extended to the assembly level as well. The AM capabilities are not limited to shape complexity, nor are they only beneficial to a part's performance. DFAM contributions-aimed at seizing these benefits-are rather scarce, but the issue is being given more and more research interest. As a matter of fact, when DFAM is considered from an assembly point of view, it is mainly for redesign cases [7]. Indeed almost none of the current works is led to the consideration of the AM benefits for assembly design in a new product development (NPD) context. Nevertheless, a few contributions [8-12] are targeted at conceptual design for AM. Furthermore, the few assembly-oriented DFAM (A-DFAM) contributions do restrict the scientific issues to part consolidation (PC) [13]. These two aforementioned situations are fully encapsulated in Yang et al.'s [11] statements: '[A-DFAM] mainly focuses on the redesign of assemblies by taking advantage of AMenabled capabilities ...' and 'The general motivation of assembly-level DFAM research is to investigate the possibility of part consolidation which brings benefits of reduced part count, enhanced performance (e.g., frictionless), and decreased cost ... '. While PC is indeed an AM-benefit that can greatly simplify an assembly, other benefits are still poorly explored. Fully functional assemblies of components can seamlessly be printed [14], with the advantages of consolidated parts, multi-material parts, moving mechanisms, electronic components embedding, and so on. The purpose of this article is to address the aforementioned gaps in the literature, namely considering assembly-level DFAM beyond PC and redesign cases. More specifically the paper aims at putting forth a thorough DFAM framework for NPD (made of multiple parts) and which considers all the assembly-related characteristics of AM. As these characteristics do vary across AM techniques and machines, another novelty of our proposal is that AM techniques and machines are selected to ease 
the product manufacturing, PC decisions are made based on these techniques' actual capabilities.

The content of the paper is organized as follows. In Section 2, the literature is reviewed, the rationale behind the proposed framework is explained, and a summary of the characteristics of AM processes is provided; the proposed methodology is presented in Section 3; demonstration on a case study is presented within Section 4; finally, conclusions and future work are drawn.

\section{Literature Review}

\subsection{Design for Additive Manufacturing}

The main capability of AM is praised for is its ability to seamlessly build virtually any shape at no extra (tooling) cost. This can explain why the vast majority of current DFAM works is targeted at part design. These contributions consist in optimizing part geometry in order to enhance performance through topology optimization or latticed design $[13,15,16]$. Other contributions are dedicated at making designers aware of the AM specific constraints in order to reduce iterations and tailor what can be designed to what is truly manufacturable.

DFAM is barely being considered from an assembly design perspective. This branch of DFAM can be split in two subbranches according to Yang et al. [11], namely consistent assembly (CA) and reduced assembly (RA). CA deals with all the design alterations that can be done to make an existing assembly printable without decreasing its number of components. RA-which is the scope of this paper-is concerned with how to take advantage of AM in order to reduce assembly complexity (through PC for instance).

The few works related to RA tend to gravitate around PC. An earliest DFAM contribution is the well-known Airbus aircraft duct [17], whose part count has been drastically reduced from 16 components (and fasteners) to one component. Another AM-based PC case study is the one made by Schmelzle et al. [18]. In order to aid designers seizing such an opportunity, some methodologies have been developed. Yang et al. [19] have presented a PC method that aims at redesigning assemblies of non-moving parts. The method requires a computer-aided design (CAD) file of the original design definition along with functional performance requirements. It is implicitly assumed that the parts of the assembly are originally secured together with conventional assembly methods. Worth mentioning in their methodology is that function integration is made by merging the product functional surfaces into a single design space. Moreover, in order to leverage AM capability beyond PC, the so-generated design space is used to define an optimized shape of the consolidated assembly. In a similar study, Rodrigue and Rivette [20] proposed a design methodology targeted at assemblies design for AM. The goal of their proposal is to assist the designer in the embodiment design stage, so that all the advantages offered by AM are considered; these include mainly PC and multi-material part. Using the Boothroyd and Dewhurst (B\&D) rules for design for manufacture and assembly (DFMA) [21], they proposed simple guidelines for PC in an AM context. In addition, once the assembly's parts that need to stand alone were identified, their geometries were optimized for functionality improvement using topology optimization. Yang and Zhao [22] have taken another look at the B\&D DFMA rules for part count reduction in the light of AM capabilities, where a new set of design rules have been put forth. These new rules were then used to propose a design framework following a screening-and-refinement strategy. In the screening step, the derived rules are used to filter a given existing assembly in order to find potential parts candidates for consolidation. The (second) refinement step consists in consolidating and optimizing the selected candidates leveraging part-related AM capabilities. The overall goal of their framework is to synthesize optimal solutions with the minimum cost-to-performance ratio by optimizing the part-material-architecture triplet. In order to automate these new rules' implementation, they developed a numerically assisted approach called part consolidation candidate detection. Given a CAD assembly model, the developed approach aims at first 
verifying the rules and secondly at finding optimal grouping solutions with the lowest number of groups.

A common characteristic of the aforementioned DFAM contributions is that they require an initial design of an assembly to be consolidated. As such, as shown for the GE fuel nozzle case [23], such work is needed for a better adoption of AM in the industry. Nevertheless, designing a right AM-friendly assembly from scratch could also be part of the road to an AM industrial establishment. A few contributions have also been made in this regard. Yang and Zhao [11] made it clear that conventional design methodologies are not suitable at prompting designers to embrace the design freedom allowed by AM. For instance, generating concepts with conventional design methods (such as axiomatic design) could not lead to products with consolidated parts and thus function integration. In order to somehow fill this gap, the authors proposed a conceptual design framework aimed at aiding design flow management in an AM context. The goal being "to stimulate designers who are novice in AM to think in an AM way". While their proposal may prove helpful at generating innovating concepts, these concepts would still need to be checked against the constraints of the actual AM techniques or machines selected to manufacture them. Similarly, Laverne et al. [10] proposed a conceptual design framework for supporting AM-enabled product innovation. Surveying such DFAM contributions, Rias et al. [24] came up with the conclusion that concepts generated for AM were only partially original with "a maximum of $75 \%$ newness". They have then proposed a five-stage creative DFAM method fostering the generation of creative concepts exploiting the unique capabilities of AM; the proposed method is somewhat based on the AM design features database presented in Bin Maidin et al. [9].

All these DFAM contributions are quite similar in that AM techniques/machines' specific capabilities and constraints are not explicitly taken into account. A situation well exemplified by one of the inputs of the PC detection algorithm proposed by Yang et al. [25]: "AM Process General Constraints". As will be shown in the following subsection, these AM characteristics vary from technique to technique. Even for the same technique, two different machines embodying it may have different constraints. For instance with the FFF machine Ultimaker 2, two parts moving relatively to each other or two mating parts made of different materials must be printed separately (and assembled afterwards). However, with a FFF Ultimaker 3 Extended machine-which is capable of multi-material printing and particularly can process sacrificial (water soluble support) material - the two components can be printed together and thus designed differently than if they were to be printed and assembled afterwards. This shows that there is a need to be aware of what techniques or machines are needed to print an assembly, while the latter is being designed.

To sum up this literature review, worth mentioning is the survey of the A-DFAM contributions, led in Yang et al. [26]. They showed that the following issues still to overcome are:

1. The lack of an analysis of what impact AM could have on conceptual design. An issue somehow addressed by the aforementioned conceptual design methods [9-12,24].

2. The lack of an explicit functional analysis (FA) method.

3. Too few decision-making decision support tools for easing PC.

4. The deficiency of functional reasoning approaches to generate AM-enabled features.

5. Too few approaches integrating manufacturing and assembly knowledge into the design stage.

We posit that point 2 cannot really be an issue peculiar to DFAM, even though we acknowledge that as for any design activity FA is paramount. Points 1 and 4 are currently being investigated, but these approaches usually prompt the designer to embrace the design freedom allowed by AM, regardless of what the actual AM techniques or machines are able to do. Therefore, while being efficient at leading to innovative designs, they are highly prone to iterations.

In this paper issues 3 and 5 are addressed. Our contribution to A-DFAM is threefold. First, in contrast to most of the aforementioned contributions, our proposal is dedicated at 
new product development (even though it may be used for redesign cases as well). Secondly, it encompasses what can be called AM-based architecture minimization, which include PC and assembly-free mechanisms as well. Thirdly, our proposal considers a manufacturing context of an "AM-factory" (i.e., FabLabs, Hubs), where many AM machines embodying different techniques are available. Particularly, the approach aims at selecting the most appropriate machine(s) for easing (possibly) a whole assembly manufacturing before this latter is fully designed.

\subsection{Additive Manufacturing Design-Related Characteristics}

The ultimate goal of DFAM is about harnessing the unique capabilities offered by AM to maximize products' performance while taking into account the constraints related to these processes to ensure a seamless manufacturing. This section is about clarifying these capabilities and constraints, and also it is aimed at providing a comparison between AM process families regarding these characteristics. In addition, this clarification is also intended to specify the levels of a product (e.g., part level), which are likely to be impacted by these characteristics. It will then provide insights into how and when to guide designers, or raise their awareness about specific aspects of AM.

\subsubsection{Assembly-Related Additive Manufacturing Characteristics}

AM is usually described as having the unique capabilities of shape complexity, hierarchical complexity, material complexity, and functional complexity [27]. All these capabilities are mostly considered at part level, except for the functional complexity, one which may be considered at product level. More specifically, at this level, the unique capabilities of AM can be enumerated as:

- Multi-material manufacturing [28]: the capability to directly manufacture multiple material components either discretely or continuously. Processes fully capable-that is, without any hardware alteration - of this property include DMD [29], LENS [30] for the metals, and FFF [31], 3DP, and PolyJet for the polymeric materials.

- $\quad$ Kinematic pair printing [14]: the capability to directly manufacture assemblies with moving parts. This has been referred to as non-assembly fabrication, in situ fabrication, or assembly-free fabrication. The printing of historical Reuleaux kinematic models [32] is a great illustration of this AM capability. Table 2 shows some kinematic pairs and specific joints, which have been additively manufactured. Critical to this capability is the clearance between the moving parts and access to these clearances for uncured or support material to be removed.

- Around insert building: in some cases it is likely that groups of components are not (or cannot be) manufactured with AM (e.g., engines, batteries, etc.), but are required to be embedded into a part. Some AM processes have this capability to be paused, for a complete part to be laid on the part being manufactured, and to be resumed. This can be viewed as another route for multi-material printing. AM techniques that have been demonstrated to build around inserts include stereolithography [33], ultrasonic consolidation [34], laminated object manufacturing [35], shape deposition manufacturing [36], and PolyJet [37].

- Electronics printing: the capability to deposit electronics components (e.g., conductive inks, sensor, etc.). This ability is somewhat related to the machine capability. In various ways, these capabilities can ease a product architecture. It is the case for the example for the Voxel 8 machine [38]. 
Table 2. Non-assembly additively manufactured kinematic pairs and joints.

\begin{tabular}{cccccc}
\hline Type & SLA & SLS & FFF & SLM & PolyJet \\
\hline Revolute & {$[39-41]$} & {$[39,40]$} & {$[42,43]$} & {$[44-46]$} & {$[47,48]$} \\
Prismatic & {$[40]$} & {$[40]$} & & & \\
Cylindrical & & & & {$[45]$} & \\
Spherical & {$[39,40]$} & {$[39,40]$} & & {$[44]$} & {$[48]$} \\
Gear & & & & {$[46]$} & {$[47]$} \\
Universal joint & {$[40]$} & {$[40]$} & & &
\end{tabular}

\subsubsection{Part-Related Characteristics}

There are number of characteristics that distinguish AM techniques as regards the features and the quality of the output without considering any post-processing step. These are described as follows:

- Material type: as shown in Table 1, materials processed by AM machines include plastics, metals, ceramics, and composites. Whereas some techniques such as SLM or LENS do only process metals, techniques such as PolyJet or SLA are limited to plastics. As such, choosing a type of material is an implicit way of selecting an AM technique.

- Resolution: the features details and minimum wall thickness of a part strongly depend on the machine resolution (XY resolution and layer height or vertical resolution). Resolution varies between techniques, and for the same technique it can also be a matter of hardware.

- Maximum size: any AM technique is limited in buildable size by the machine embodying it, therefore so are the parts (or the number of parts) that can be manufactured at once. This limitation may lead to break down the CAD model to manufacture it in smaller chunks and then reassemble them afterwards [49]. The largest AM machines have built dimensions ranging from $90 \times 60 \times 30 \mathrm{~cm}$ (Merke IV) to $40 \times 10 \times 6 \mathrm{~m}$ (Windsor) and even to (theoretically) infinite dimensions. Knowing which machine will manufacture the part before designing it will definitely restrain the design space, and conversely with a rough idea of the overall dimensions of the part a proper machine may be selected.

- Surface quality: number of factors do affect part's surface finish. Owing to the layerwise manufacturing method peculiar to AM, stair step effect makes orientation and layer thickness very influential regarding surface finish. On a single part, many different surface finishes may be encountered, varying by a more than nine factors in terms of roughness (Ra). Nevertheless, the technique itself does also influence the surface quality. In techniques processing plastics for instance, SLA machines do provide a better surface quality than FFF ones; in metals, SLM parts have better quality than those manufactured with LENS.

\section{Assembly-Oriented Design Framework for AM}

When considering AM at product level, the ultimate goals that should be sought are:

- The possibility to consider parts consolidation, in order to minimize the product architecture.

- The consideration of assembly-free mechanisms [39,40], that is, assemblies (of moving parts) that can be printed at once and which after a few minor post-processing tasks (e.g., support removal, surface polishing, etc.) are ready for use.

The aim of this research is to provide a methodology for seizing these opportunities by the conceptual design stage of the product. In other words, the methodology aims at seizing these benefits before a detailed geometry of the product is defined. As shown in the assembly-related AM characteristics section, these goals can be reached for single material mechanisms with some AM machines. Furthermore, multi-material products can be printed by AM machines such as PolyJet machines or the Voxel8 which, during the same print job, can process multiple polymers (including hard, soft, and flexible) and print 
electronics components as well. However, as the previous analyses have shown, none of the available AM techniques are capable of all the enumerated assembly-related characteristics at the same time. Besides, some components in a product may prove more economically viable if manufactured by conventional processes or simply if outsourced. For these reasons we posit that:

- Owing to the heterogeneous nature of a product, assembly-free AM is not, generally, possible in the current state of the art. The AM of a product may involve many techniques, even in some cases other conventional manufacturing processes as well (hybrid manufacturing [50]), and a few assembly operations.

- The possibility to consider part consolidation cannot be made regardless of the specific characteristics of available AM techniques.

The goal that should, therefore, be sought is to find a product architecture, or an engineering bill of materials (eBOM) in case of redesign, which is minimal (while still functional) - that is, with the least separate components-and which is manufacturable with a single AM technique or with the least AM techniques. Besides, once the product architecture is minimized, a strategy must be retained for the way the parts will be designed to take advantage of the selected AM techniques' characteristics. Our strategy is that, once the part's functional interfaces (i.e., surfaces, lines, etc.) are identified, these are connected both to ensure structural integrity and a proper conveyance of the flows getting through the part, abiding by any design space and manufacturing constraints. Thus, AM-friendly parts' geometries can emerge.

\subsection{Overall Description}

At the core of the proposed assembly-oriented design framework for AM are the aforementioned premises. The framework is dedicated at helping designers mainly through embodiment and detail design stages. It aims for three main goals:

1. Ensuring that the product architecture is kept to its supreme boundary by considering the available AM techniques and machines specific part consolidation capabilities.

2. Determining a manufacturing plan along with any in situ (during manufacturing) or subsequent assembly operations.

3. Providing critical geometric elements building the design space-such as functional interfaces and volume-envelopes-(based on the architecture and the manufacturing plan) to be used for the detail design of the parts.

As shown in Figure 1, these goals are reached through three main steps, which are described in the following sections. Since the framework is adapted for new product development, the way functional analysis is to be conducted is first described for the sake of clarity and consistency.

\subsection{Initial Product Architecture Derivation}

The framework is dedicated to new development of products mainly manufactured and assembled with AM. As such, it is intended to guide the product architect and designer from the overall functionality statement of the product to the detailed design of the product. A first stage is to get an enhanced product architecture from a comprehensive functional analysis (both external and internal). This stage is structured in three steps described as follows.

\subsubsection{Functional Analysis}

The product environment-that is, everything it is to interact with in order to fulfil its functionality - is analyzed and enumerated (e.g., human, air, raw material, etc.) in terms of external elements (EEs). Such analysis can be summarized using a diagram like the one presented in Figure 2a (for the gripper case study). In this case study, EEs include the user's hand, the object to clamp, and the environment that the product is surrounded by. Two kinds of top level functions are then to be identified: main functions, which are those whose 
action is related to two EEs, and constraints functions, which act on a single EE (as shown in Figure 2a), these do not actively participate in the overall functionality but are required for the product to be conveniently usable (e.g., maintain gas tightness, stand on a plane platform). The flows (i.e., energy, material, or signal) to be conveyed by the product are enumerated. Using standardized basic functions from the Reconciled Functional Basis [51], each top level function is decomposed to its lowest level and the basic functions derived from it are arranged in an order allowing the fulfillment of the overall function. Finally, the flows are routed through all the standardized functions. The outcome of this step can be summarized with a block diagram (see Figure 2b).

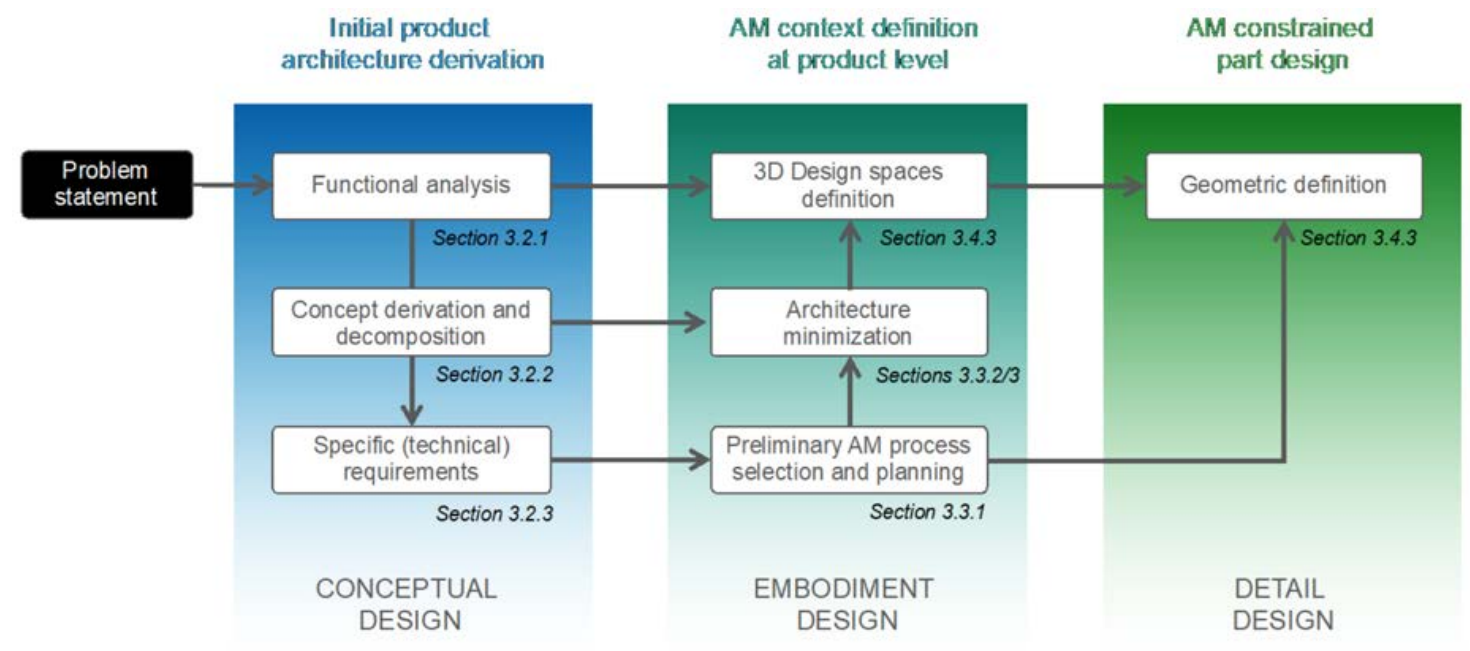

Figure 1. Flowchart of the assembly-oriented design framework for AM (blue boxes relates steps, green ones represents input/output information).

\subsubsection{Concept Derivation and Decomposition}

A concept is derived for the product with a close attention to the fact that each basic function is fulfilled by one or many components and that many components may fulfil a single function. The derived concept is abstracted with a product architecture that combines three views:

- Part-to-part kinematics relationships view: all the parts are enumerated and the kinematic pair between them are specified.

- Functional flows view: components in the part-to-part relationships graph are first clustered according to the basic functions they fulfil, and then the corresponding flows are routed from the EEs through the components. Some flows may have to be split, while others may be required to merge. Spatial relationships view: using the mereotopological primitives descriptors to describe the physical connections between spatial regions (denoted $x$ and $y$ ) such as developed in Demoly et al. [52] as " $x$ is part of $y$ ", " $x$ is internal part of $y$ "(IP), " $x$ is tangent of $y$ ", and " $x$ overlaps $y$ ". Such descriptors provide complimentary information on relationships between non-relatively moving parts specified.

\subsubsection{Specific (Technical) Requirements}

Specific information is added for the components. Firstly, maintenance/repair requirements and production requirements (i.e., 3D printable, not to be 3D printed, or outsourced component) are specified. Then for each part, candidate to AM, a number of desired characteristics are to be specified. These characteristics (or requirements) are used to generate suitable AM techniques and materials. Figure 3 delineates a data structure for the characteristics of a part to be additively manufactured, along with some values of the characteristics. It is worth highlighting that some of these characteristics (such as minimum 
wall thickness for instance) are conventionally known after a part's detailed geometry has been made, or these may be constraints set by the available AM machines. However, in our proposal, the designer using the approach is prompted to think about them beforehand, and to somehow commit to them. Nevertheless, not all the characteristics must be specified, one may choose to simply ignore the less crucial ones; the aim of that strategy is to get the proper AM techniques that will manufacture the parts and design the product geometry accordingly (and avoid time consuming design iterations). This choice is consistent with the proactiveness of the proposed approach: the way(s) the product is to be additively manufactured will be known before efforts are put into its detailed design, so that the designer is aware of how the designs can fully leverage the specific capabilities of the selected AM techniques while abiding by their constraints. In addition, to direct detailed design, these specific requirements will also be used to influence decisions made about part consolidation.

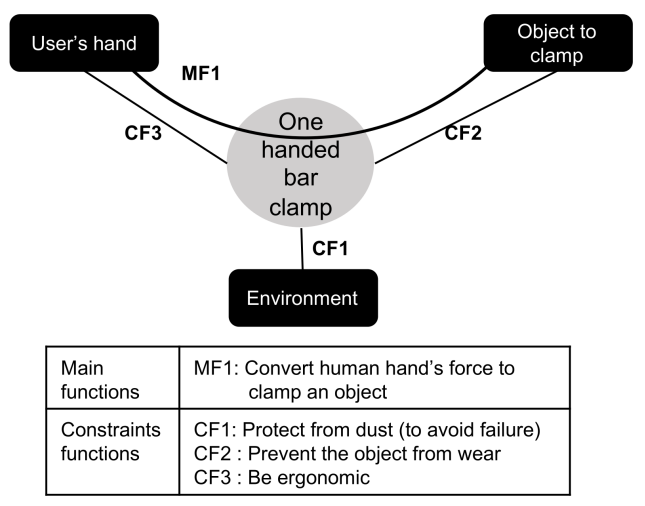

(a)

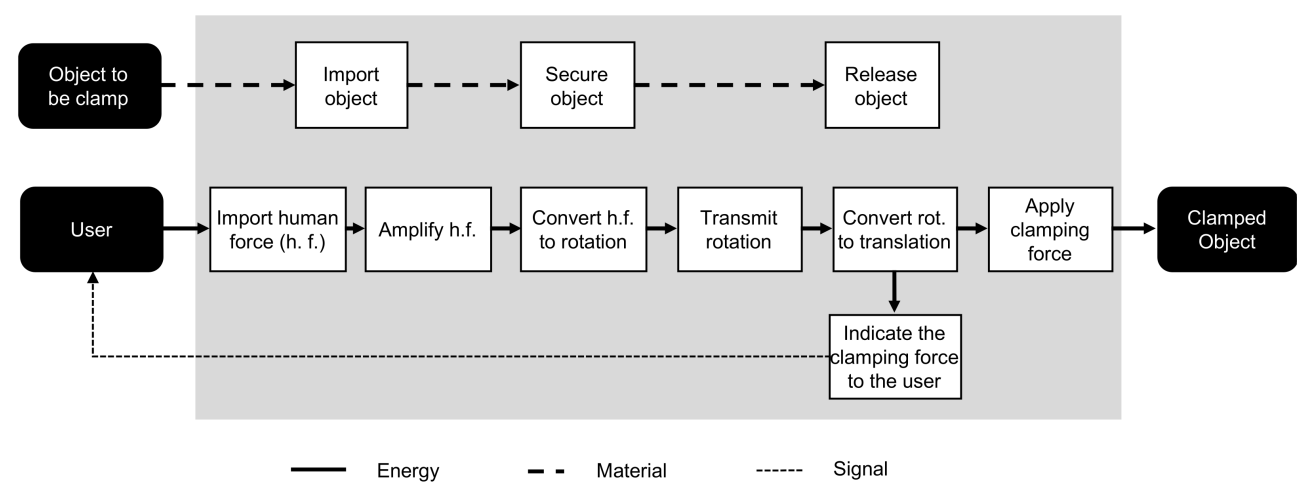

(b)

Figure 2. Clamp's functional analysis. (a) External functional analysis; (b) Functional decomposition.

The pieces of information contained in the derived initial product architecture are:

- For the parts themselves: indication of whether the component will be outsourced or is not to be additively manufactured (e.g., battery, engine, bearings, etc.), indication of whether the component would need to be maintained (in case of a weary component) or often moved, characteristics for AM techniques/machines selection.

- $\quad$ For the part-to-part relationships: kinematic pairs, spatial relationships, and flows. 


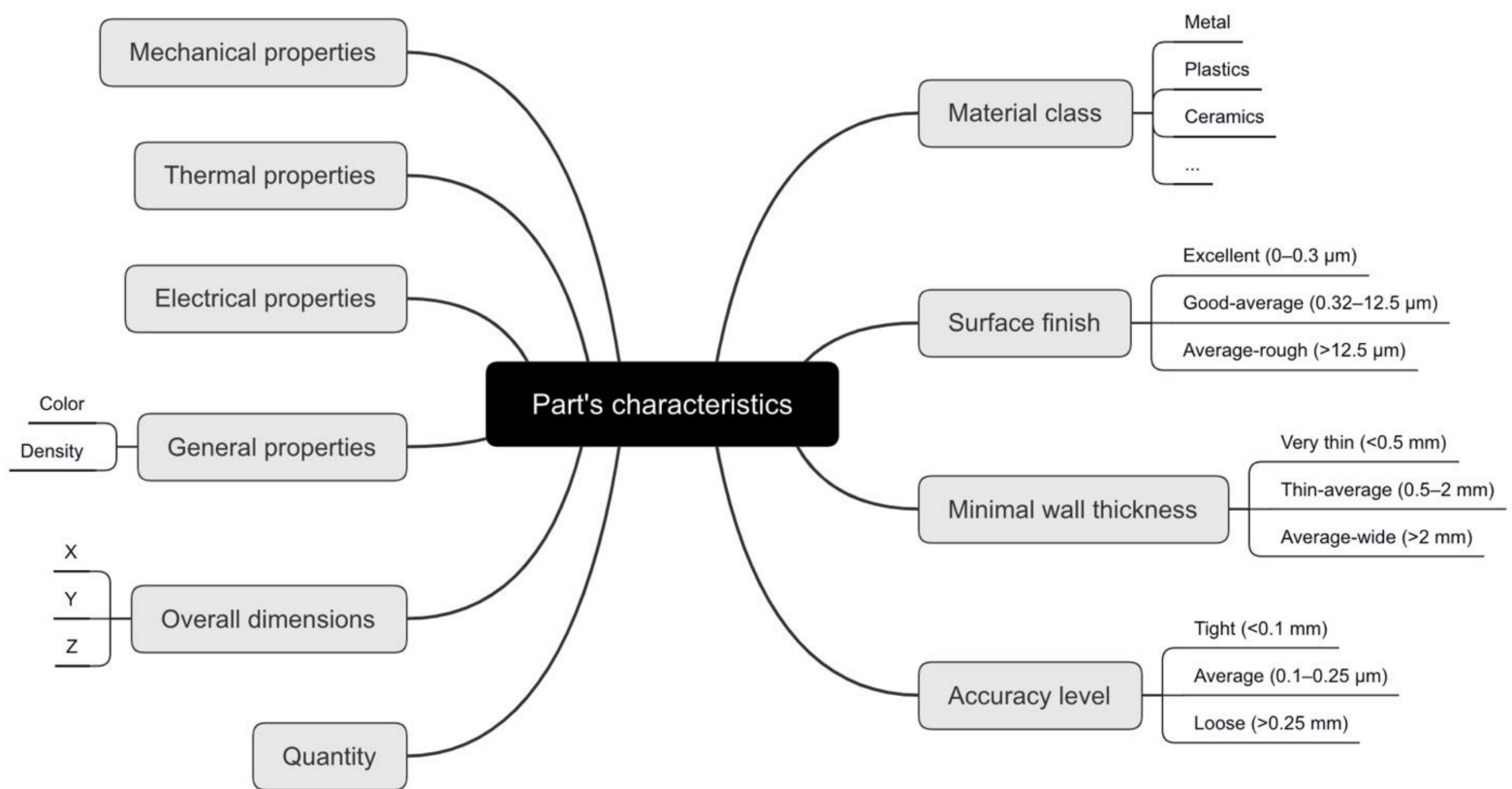

Figure 3. Part characteristics for AM techniques selection.

\subsection{AM Context Definition at Product Level}

We define a minimal product architecture as an architecture containing the minimum necessary separate parts. This stage of the methodology is intended to make sure that AM capabilities and constraints are taken into account at product level by setting up an AM context. More specifically it aims at:

- Determining an architecture with the least components based on the available AM techniques' capabilities.

- Maintaining functionality regardless of how parts have been combined.

- Determining a manufacturing plan (including assembly operations) so that the detailed design stage is made accordingly, abiding by the selected processes' constraints. Another rationale underpinning this goal is that, those components that are to be manufactured together (be them moving relatively to each other or not) must be designed together (or at least with the same awareness of how manufacturing will occur), since manufacturing direction will be the same for them.

As the product concept is generated regardless of any conventional manufacturing constraint, it is likely that standalone components have to be so for various reasons (i.e., functionality, maintenance, etc.). As such, a product architecture-which is derived within a AM context-may already be a minimal one, that is, without unnecessary standalone components like fasteners. However, to ensure that unnecessary standalone components are eliminated, any architecture should be checked, and the framework can be used for that purpose. It is notable that the method may also be used for redesign cases where the product has been originally designed to be manufactured by conventional processes.

Hence, setting an AM context is based on the initial product architecture (as described in Section 3.2) and it requires knowledge about the specific characteristics of the available AM techniques (as described in Section 2.2). The stage is organized in three steps.

\subsubsection{Preliminary Processes Selection and Manufacturing Plan Generation}

A number of studies have been carried out about AM process selection for parts $[53,54]$. As this aspect is not the core of our proposal, we elected to build on previous work addressing this issue. This preliminary technique selection is achieved through two substeps:

1. Materials and techniques selection for each part individually based on the specific requirements stated for each of them. This is where research work from Ghazy [53] on a decision support system has been harnessed to our contribution. 
2. Techniques selection for the whole assembly. Each of the part to be additively manufactured is likely to be manufacturable by more than one AM material-technique combinations. This substep is, basically, intended to determine the combinations that will suit most of the parts, as a way to streamline the manufacturing of the whole assembly.

The procedure for techniques and materials selection at part level is made through two main steps as depicted in Figure 4. Requirements on the part that has an influence on the AM technique are first used to generate a set of feasible techniques (among the available AM techniques); these requirements are used to find techniques satisfying them individually, then the so-found sets of techniques are crossed to find techniques meeting all the requirements. In case there is no available techniques meeting all the requirements, those which are conflicting are highlighted and either they are edited or the part is deemed not manufacturable by the available AM techniques. Each technique has a set of required materials that it can process. Techniques generated from the first step, along with parts requirements related to materials used to select techniques and materials combinations possible for the part. Similarly to the previous step, when no combination is found, either material requirement is edited or the part is deemed not additively manufacturable.

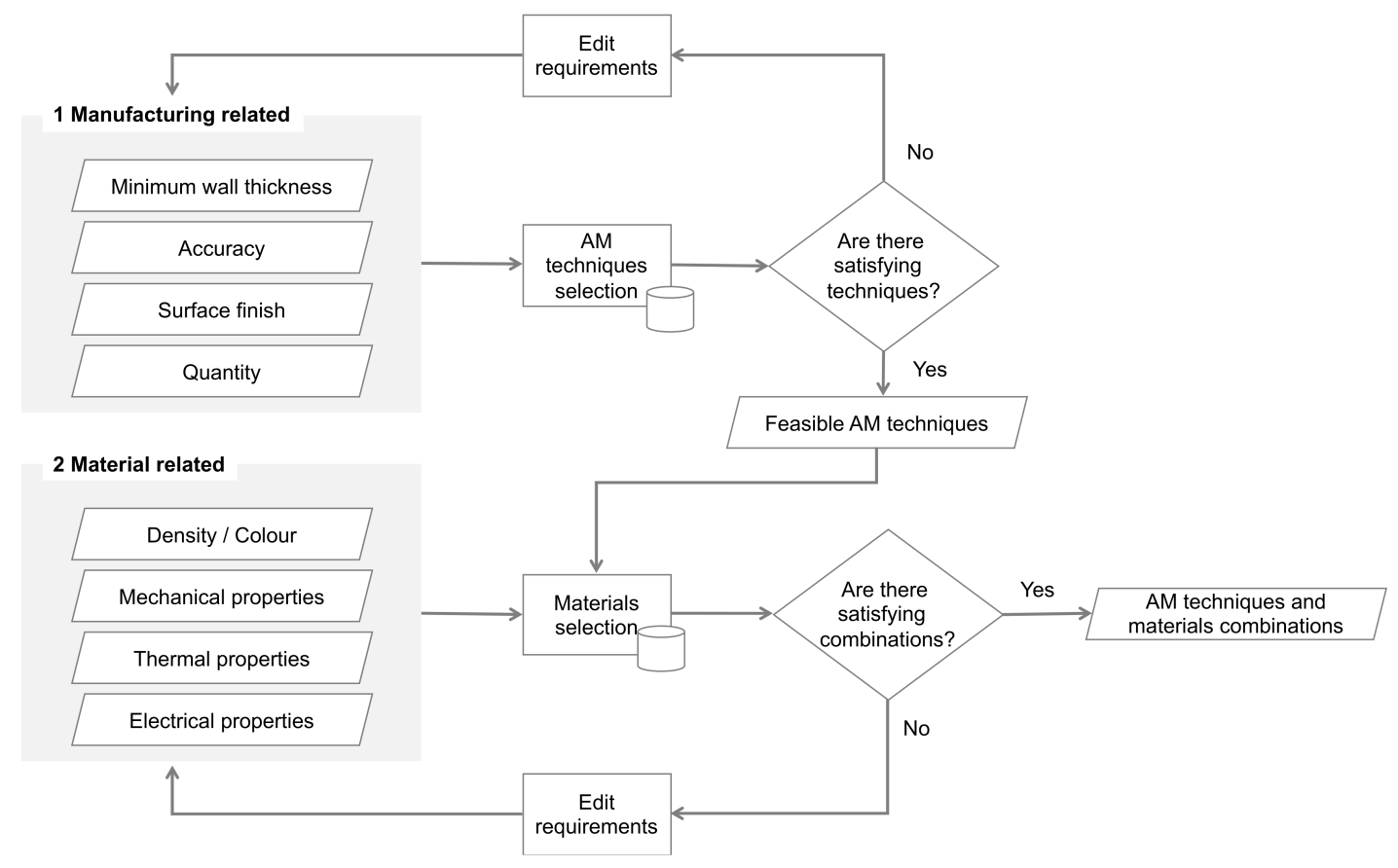

Figure 4. AM preliminary techniques selection (at part level).

For each component $C_{i}$, candidate to AM (that excludes outsourced components or those required to be manufactured by a conventional process), a set $S_{i}$ of available AM techniques that can, possibly, manufacture it, is therefore generated. As an attempt to streamline the product manufacturing, the maximum intersection of the selected AM techniques sets (that is, the largest set where the sets $S_{i}$ overlap), which is denoted $S$, is determined. $S$ is then ranked according to the assembly related characteristics described in Section 2.2.1. The best process is then selected and designated as the main AM technique. The same procedure is repeated for the remaining components (those whose $S_{i}$ elements are not included in $S$ ) to find a secondary AM technique. The process may be repeated again in case there are still parts not manufacturable by the selected secondary AM technique. In order to keep the manufacturing scheme simple, a criterion for limiting the number of repetition - that is, the number of secondary AM techniques-is decided. In case where the criterion does not met either the requirements on parts revised, or the whole concept is deemed as not easily additively manufacturable and have to be altered. 
At the end of this stage, a new view is then generated for the product architecture: a manufacturing view indicating whether a component is manufacturable by the main AM technique, manufacturable by a secondary AM technique, or not additively manufacturable.

\subsubsection{Architecture Minimization between Mating Components}

Once the techniques by which components are to be manufactured are determined, decisions are made both about how they can be consolidated to generate a minimal architecture and how the whole product will be manufactured and assembled. In others words, the purpose of this step is to provide an answer to the following question: given two parts non-moving relatively to each other, how can these parts be consolidated in order to simplify the product architecture? As shown in the bottom of Figure 5, three outcomes can result from this analysis: either the parts are simply merged (Consolidated assembly), or one of the part is laid inside the other, while this latter is being manufactured (assembly with part embedding), or they are regularly assembled. The process is as follows:

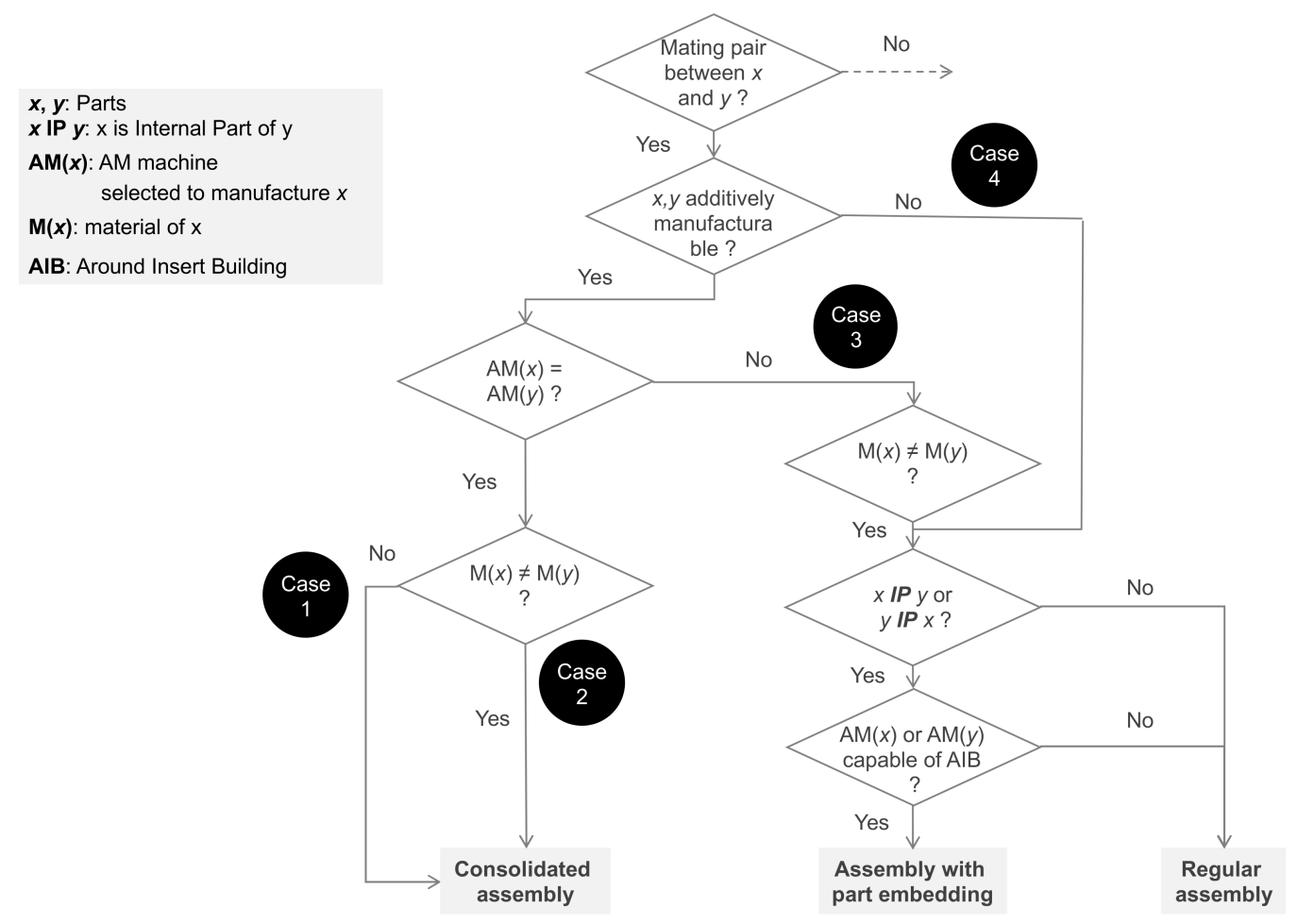

Figure 5. Decision ladder of the product architecture minimization through mating pairs.

1. Components without relative motion are first clustered within sub-assemblies.

2. Consolidation is made by components pairs comparisons in each sub-assembly. The components are subsequently denoted by $x$ and $y$. Four cases can then occur, as regards manufacturing and materials requirements:

- Case 1: components are of the same material and are manufactured by the same AM technique $(\operatorname{AM}(x)=\operatorname{AM}(y)$ and $\mathrm{M}(x)=\mathrm{M}(y))$. In such case, they are simply merged as a single component and their respective functional flows are combined.

- $\quad$ Case 2: components are of different materials processed by the same technique $(\operatorname{AM}(x)=\mathrm{AM}(y)$ and $\mathrm{M}(x) \neq \mathrm{M}(y))$. In that case, they are also merged and flows are combined.

- $\quad$ Case 3: components are of different materials processed by different techniques $(\mathrm{AM}(x) \neq \mathrm{AM}(y)$ and $\mathrm{M}(x) \neq \mathrm{M}(y))$. In this case, spatial relationships between the components (read from the architecture spatial relationships view) along with the abilities of the two techniques of building around insert are used to make a decision as shown in Figure 5. The two parts are either tangent or overlapping at 
some region. In case they are tangent, they are simply manufactured separately and regularly assembled (requiring therefore assembly features for a rigid kinematic pair). If they are overlapping, let us denote 2 , the outermost component in the regions where the parts are overlapping. If the technique manufacturing 2 is capable of building around insert, then 1 and 2 are assembled in such a way that 1 is embedded in 2, while this latter is being manufactured, otherwise they must be regularly assembled, that is, manufactured separately and assembled afterwards.

- $\quad$ Case 4: one of the components is outsourced or non-additively manufacturable. We assume that two adjacent outsourced components are considered as a single outsourced component, the case where both compared components are outsourced is thus excluded. In case the parts are overlapping and the outermost component is the outsourced one, then the parts are regularly assembled. Otherwise, the outcome is the same as for Case 3.

\subsubsection{Architecture Minimization between Moving Components}

Components moving relatively to each other are conventionally manufactured separately and assembled afterwards; however, as shown in Section 2.2, depending on the kinematic pair linking them and the selected AM techniques, the adjacent components can be manufactured together while still be able to move relatively to each other. This step is about identifying all these moving components that can be manufactured together. It will have implications on the final design, in that manufacturing a joint may require a particular orientation and consequently alterations of a conventional joint's design [39]. The step is conducted by comparing pairs of moving components $\mathrm{A}$ and $\mathrm{B}$, which are related by joint $\mathrm{J}$ : A-J-B. The possible situations are as follows:

- $\quad \mathrm{A}$ and B are manufacturable by the same technique. If kinematics pair J is also manufacturable by the technique, then the whole assembly is consolidated during manufacturing. Otherwise - that is, if the kinematics pair is not manufacturable-the components are assembled afterwards and assembly features must be integrated in their designs.

- $\quad \mathrm{A}$ and $\mathrm{B}$ are not manufacturable by the same technique (or one of the parts is not an AM part). In that case, they are assembled normally.

As depicted in Figure 6, at the end of this stage, the enhanced product architecture derived in the previous stage (Section 3.2) has been used to generate a minimal architecture and a manufacturing plan based on the available AM machines capabilities. The derived minimal architecture shows parts that have been combined, flows that have been merged. The manufacturing plan tells which part is to be manufactured by which AM machine and how the part is to be assembled. The minimized architecture and the manufacturing plan are then the basis of the parts design stage, which is described in the next subsection.

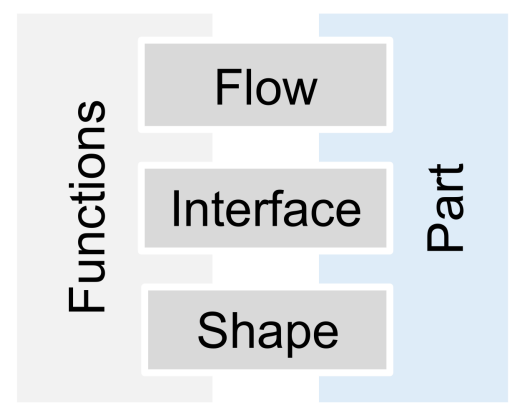

Figure 6. Elements characterizing a part. 


\subsection{AM Constrained Part Design}

3.4.1. The Case of Mechanisms to Be Manufactured by the Same Process, in a Single Print Job

It is likely that groups of components, moving relatively to each other or not, are to be manufactured and assembled together (it is actually one of the sought goals of our proposal). This case has been covered in Sossou et al. [55]. The methodology there proposed can be summarized as:

1. Product architecture 3D laying out: the design space of each part is defined and accordingly positioned.

2. Functional interfaces definition: based on the part-to-part kinematics relationships, the design spaces are updated with the proper functional interfaces (FIs).

3. AM contextualization: a step that consists in setting clearances between FIs, choosing a printing configuration, choosing a printing orientation, and allowing access to the clearances.

4. Components' geometries designs.

For more details, the reader is advised to refer to [55].

\subsubsection{Foundations of Our Strategy for Harnessing AM Shape Complexity to Part's Performance}

Any system, sub-assembly, or component is designed to fulfil a function that represents what the device must do. The device shape, form, or architecture answers the question of how the function is fulfilled. This shows why a device function must be fully understood before time is spent on its embodiment design. Tightly related to a device's function is the notion of flow, which basically is what the device operates on for the function to be fulfilled. Systems, even those made of a single component, rarely fulfilled their function(s) in an isolated manner. In other words, they always fulfil their function by interacting with their surroundings (be it made of a user or others components) by means of one or several flows exchange. The interaction between a component and its surroundings occurs at its interfaces, which can be seen as the flows "gates". It can be summarized that a component is fully defined firstly by its functions (which is what it does), the flows it processes for the functions to be fulfilled, its interfaces through which the flows are exchanged, and its shape holding the interfaces together. This breakdown of component is depicted in Figure 6.

Once flows getting through a component are identified, it is of interest to determine what impact (if any) they have on the shape and interfaces of the component. At their lowest level of specificity, flows are either energy, material, or signal [51,56]. Functions associated with material flows are basically functions that process the materials by somehow changing its state. These are categorized by Ullman [57] in three groups: through flow functions (e.g., rotate, translate, move, lift, channel, etc.), diverge flow functions (disassemble and separate), and converge flow functions (mix and attach). A component fulfilling such function must "clear the way" for the materials and as such its shape is not crucial for the flow conveyance. However, when the processed flow is energy, say in a mechanical form (load for instance), it is obvious that shape, along with interface, play a key role.

Ullman [57] has stated that: "It has been estimated that fewer than $20 \%$ of the dimensions on most components in a device are critical to performance. This is because most of the material in a component is there to connect the functional interfaces and therefore is not dimensionally critical. Once the functional interfaces between components have been determined, designing the body of the component is often a sophisticated connect-the-dots problem". The premise governing the methodology proposed to leverage AM shape complexity capability to design effective components is profoundly related to that statement. The extra $80 \%$ of components' dimensions that are not critical to the performance may be due to conventional (subtractive) processes' limitations. Furthermore, to better suit our approach, the statement can be extended as " ... a sophisticated connect the dots problem in order to assure a structural integrity and a proper conveyance of the flows related to the component's functionality". A strong statement in Ulman [57], highlighting the importance of interfaces, in agreement with the aforementioned statement and which is worth quoting reads: "Components grow primarily from interfaces". 
In a nutshell, a component is bounded by its FIs, these must be connected to ensure structural integrity and to ensure that flows entering or leaving interfaces are conveniently conveyed. The AM shape complexity gives way to ensure that connectedness with the bare minimum matter. This minimalist vision of part design is illustrated in Figure 7 for an aircraft hinge plate; a comparison is made between how this component has been designed for conventional processes and how it could have been designed for AM.

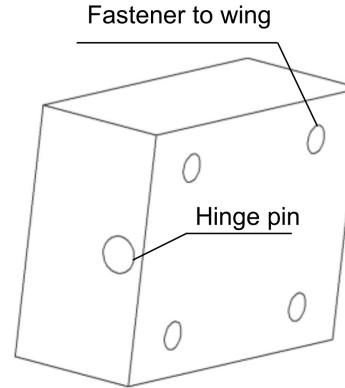

(a) Solid block

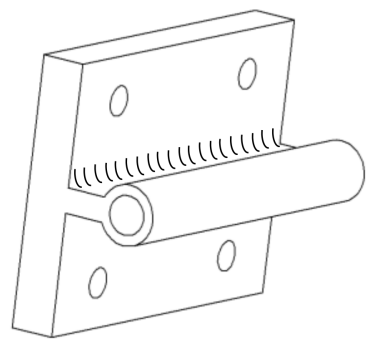

(b) Welded

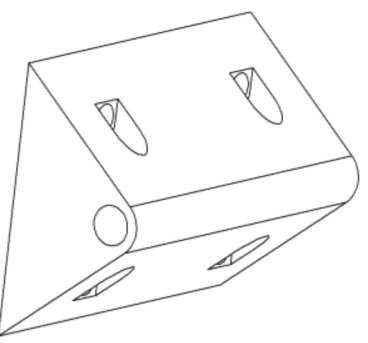

(c) Machined structure

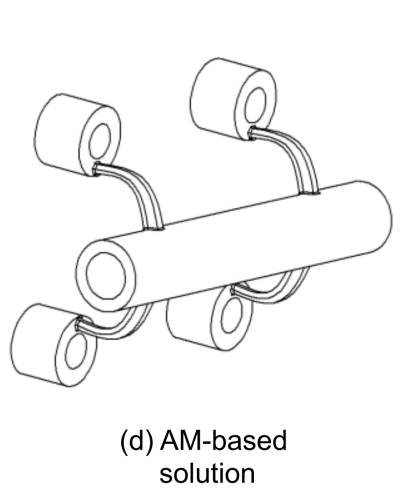

d) AM-based solution

Figure 7. Aircraft hinge plate designs according to various manufacturing processes including AM.

\subsubsection{The Proposed Methodology for Part-Oriented DFAM}

Consistent with the aforementioned philosophy, a five-steps strategy is proposed to design the geometry in a minimalist way, as outlined in Figure 8. The selected AM techniques constraints are taken into account as well. The strategy is illustrated in Figure 8 with a vise's frame. First, the component's FI shapes are drawn. Second, the FIs' shapes are thickened into functional volumes (FVs); the thicknesses can be governed both by resolution of the considered AM process and tolerances related to the considered FIs. In the third step, paths joining the FVs are defined; this can be done either to ensure the component's connectedness, or to ensure a way for a specific flow (or even a combination of flows), or both. To allow for the subsequent parametric optimization to generate a proper path for the connecting element, this curve can be parameterized. This could be done, for instance, by creating a curve as a spline through three points and by using the four middle point coordinates in a plane as parameters. Fourthly, the connecting elements' shapes along the previously defined paths are designed. To improve the performance of the component, the section can be of different types including solid cross-section, solid cross-section with lattice structure, hollowed cross-section, hollowed cross-section with lattice structure, etc. To avoid sharp corner (and equivalently, stress concentration), corners are smoothed in the fifth step. Each of these steps leads to some geometric parameters. Those are then finally optimized to generate a component that behaves and conveys the flows appropriately. The following scheme has been retained for the parametric optimization:

1. Choice of each parameters bounds.

2. Specification of any constraint on the parameters. These can be geometric constraints such as relationships between parameters, or constraints ensuring a proper behavior such as maximum stress or minimal natural frequency. The functional flows conveyed by the part on one hand, and the chosen material on the other hand can provide indication on what constraints related to an appropriate behavior must be met.

3. Definition of the component's mass as an objective function. Choosing the component's mass as an objective function to minimize is consistent with the endeavor to design components with the bare minimum matter. Other objective functions that are sensitive to the chosen parameters and that are relevant to the sought performance may also be chosen. 


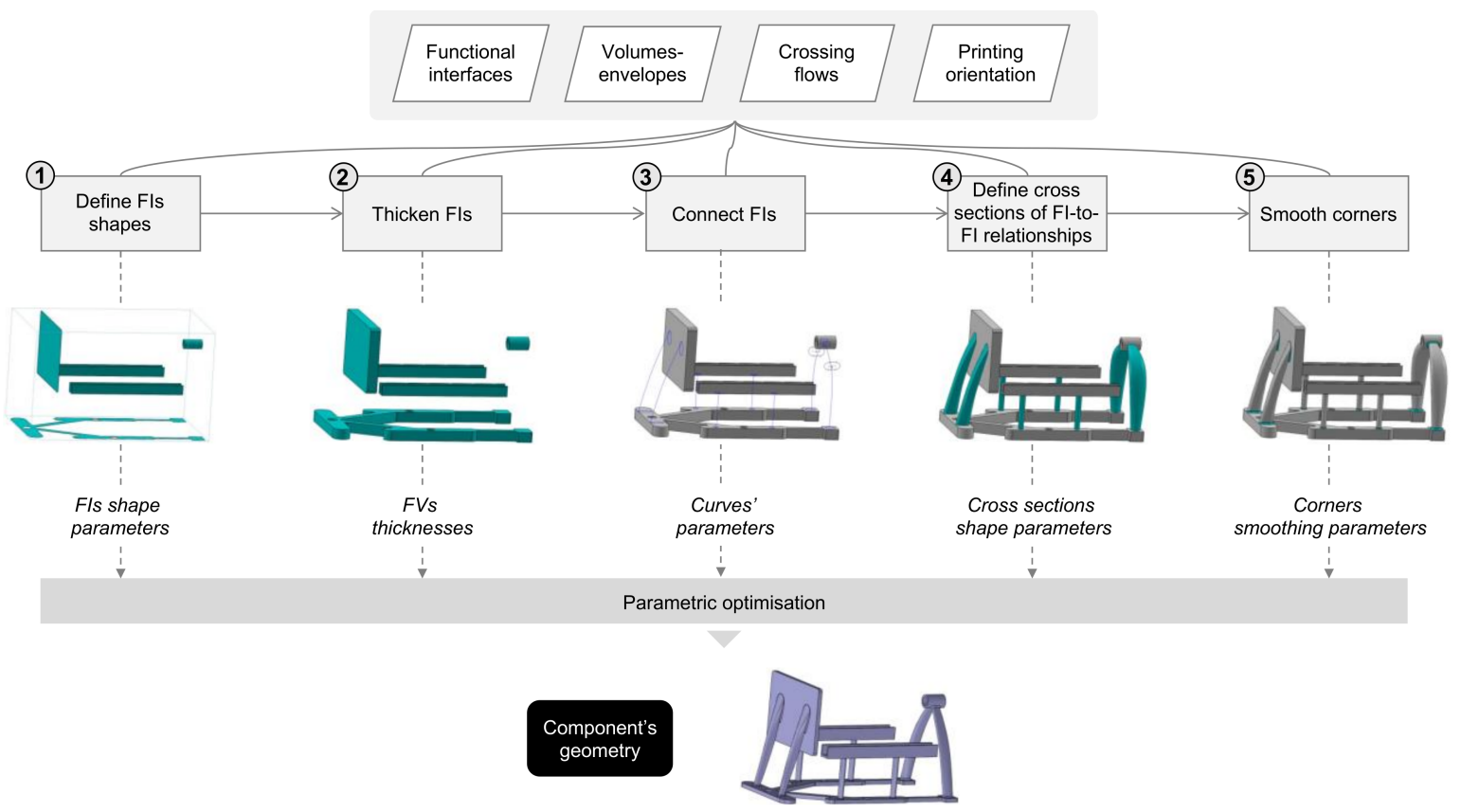

Figure 8. The proposed design methodology for part's design illustrated via a vise's frame based on prior research work [56].

\section{Case Study}

The proposed framework has been illustrated with a one handed bar clamp, similar to the one that is discussed in Chapters 7 and 9 in Ullmann [57]. The main steps have been shown hereafter.

\subsection{Initial Architecture Derivation}

After a functional analysis (see Figure 3), as explained in Section 3.2, and generation of a concept, an architecture with 17 components have been retained. The eBOM of the design concept, along with the requirements for each component, can be found in Table 3. Figure 9a shows the part-to-part kinematics relationships view combined with the functional flow view. In Figure 9, edges representing a kinematic relationship are tagged with the name of the kinematic pair involved, the other edges represent the functional flows as indicated in the legend.

Table 3. Parts' requirements.

\begin{tabular}{|c|c|c|c|c|c|c|c|c|c|}
\hline \multirow[b]{2}{*}{ ID } & \multirow[b]{2}{*}{ Part Name } & \multirow[b]{2}{*}{ AM } & \multirow[b]{2}{*}{ Material Class } & \multirow[b]{2}{*}{ Surface Finish } & \multirow{2}{*}{$\begin{array}{l}\text { Min Wall } \\
\text { Thickness }\end{array}$} & \multirow{2}{*}{$\begin{array}{l}\text { Accuracy } \\
\text { Level }\end{array}$} & \multirow{2}{*}{$\begin{array}{c}\text { Dimensions } \\
(\mathrm{mm})\end{array}$} & \multicolumn{2}{|c|}{ Mechanical Properties } \\
\hline & & & & & & & & $\begin{array}{l}\text { Yield } \\
\text { Strength }\end{array}$ & Durometer \\
\hline 1 & Main body & Yes & Plastics & Average-rough & Thin-average & Average & $\begin{array}{c}100 \times 150 \times \\
30\end{array}$ & 10-20 MPa & Shore D $60-70$ \\
\hline 2 & Trigger & Yes & Plastics & Average-rough & Thin-average & Average & $40 \times 90 \times 30$ & $10-20 \mathrm{MPa}$ & Shore D $60-70$ \\
\hline 3 & Bar & No & & & & & & & \\
\hline 4 & Tail stock & Yes & Plastics & Average-rough & Thin-average & Average & $50 \times 50 \times 30$ & $10-20 \mathrm{MPa}$ & Shore D $60-70$ \\
\hline 5 & Lock & Yes & Plastics & Average-rough & Thin-average & Loose & & & \\
\hline 6 & Pad1 & Yes & Plastics & Good-average & Thin-average & Loose & & & Shore A $40-100$ \\
\hline 7 & Pad2 & Yes & Plastics & Good-average & Thin-average & Loose & & & Shore A $40-100$ \\
\hline 8 & Roll pin & Yes & Plastics, metals & Average-rough & Average & & & & \\
\hline 9 & Knurled pin & Yes & Plastics, metals & Average-rough & Average & & & & \\
\hline 10 & Release trigger spring1 & No & & & & & & & \\
\hline 11 & Release trigger spring2 & No & & & & & & & \\
\hline 12 & Release trigger & Yes & Plastics, metals & Average-rough & Thin-average & Average & & $10-20 \mathrm{MPa}$ & Shore D $60-70$ \\
\hline 13 & Power spring & No & & & & & & & \\
\hline 14 & Jam plates1 & Yes & Plastics, metals & Average-rough & Thin-average & Average & & 10-20 MPa & Shore D $60-70$ \\
\hline 15 & Jam plates2 & Yes & Plastics, metals & Average-rough & Thin-average & Average & & $10-20 \mathrm{MPa}$ & Shore D $60-70$ \\
\hline 16 & Split pins1 & No & & & & & & & \\
\hline 17 & Split pins2 & No & & & & & & & \\
\hline
\end{tabular}




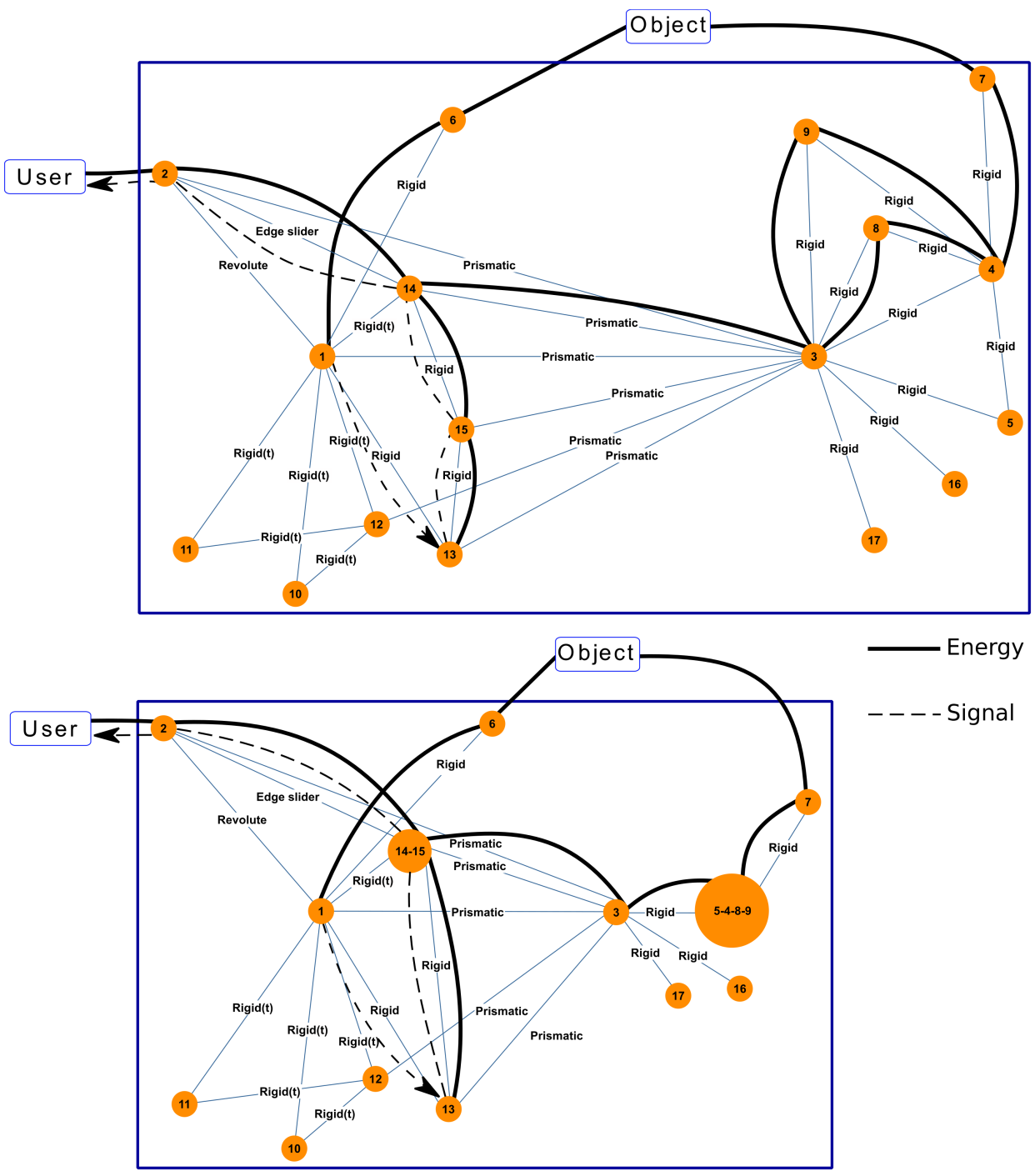

(a)

(b)

Figure 9. Product architecture showing part-to-part kinematic pairs along with functional flows: (a) initial architecture and (b) minimized architecture.

\subsection{Minimized Architecture and Manufacturing Plan}

We used a scenario of an AM factory that has six machines based on the following techniques: FFF, SLA, PolyJet, and SLS. Details of the available machines can be found in Appendix A. All parts candidate to AM were found manufacturable with the available machines. Based on the assembly-related characteristics, and especially the capability to build around inserts, the Ultimaker 3 Extended (U3E) machine has been found to be the best AM machine. The combination U3E-PLA has been selected for the components: $1,2,4,5,8,9,12,14$, and 15 (see Table 3). For components 6 and 7 (pads), a different material-TPU 95A-was selected; it is a semi-flexible and soft (shore A 95) material with high wear and tear resistance. These choices have led to a generated minimized architecture with 13 separate components, as shown in Figure 9b. The manufacturing plan is delineated in Table 4. 
Table 4. Manufacturing plan.

\begin{tabular}{llll}
\hline Operation & $\begin{array}{l}\text { Part or } \\
\text { Sub-Assembly }\end{array}$ & Machine-Material & Comment \\
\hline \multirow{2}{*}{$\begin{array}{l}4-5-8-9 \\
14-15\end{array}$} & $\begin{array}{l}\text { Ultimaker 3 } \\
\text { Extended-PLA }\end{array}$ & $\begin{array}{l}(1,2,5) \text { in situ assembly } \\
\text { In situ assembly for 1-2 and 1-12 }\end{array}$ \\
\hline 2 & 6,7 & $\begin{array}{l}\text { Ultimaker 3 } \\
\text { Extended-TPU-95A }\end{array}$ & Regular assembly after AM \\
\hline 3 & $3,16,17$ & (not AM) & Regular assembly to (4-5-8-9) \\
\hline 4 & $10,11,13$ & (not AM) & Regular assembly to (1-2-12) and 3 \\
\hline
\end{tabular}

\subsection{Final Design}

The generated minimal architecture has been used to designed the components' geometries. A proprietary tool—the Pegasus CAD Assistant from Demoly et al. [2], was harnessed to semi-automatize the generation of the design spaces and the functional interfaces based on the kinematic relationships as shown in Figure 10a.

(a)

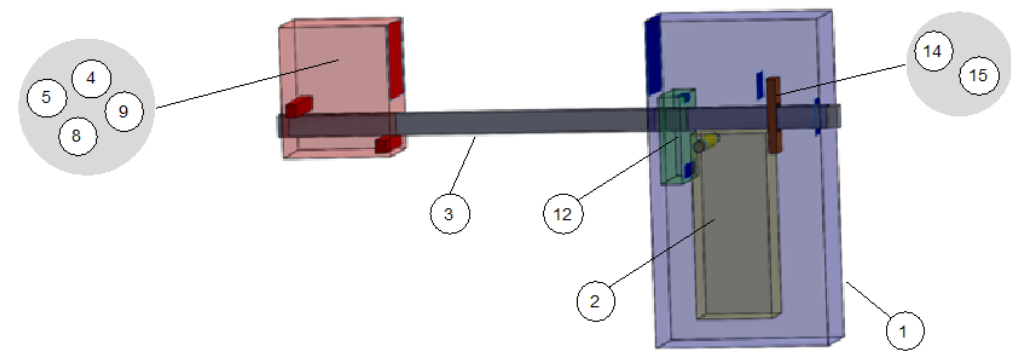

Design spaces

Detailed design

(b)

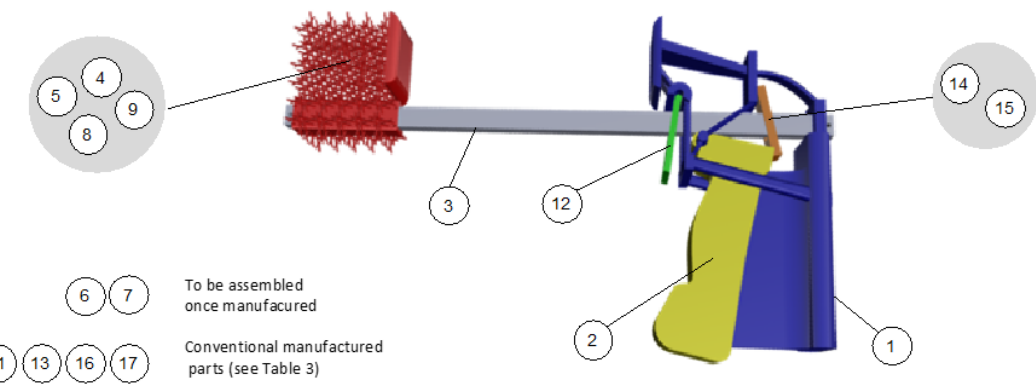

Figure 10. (a) Design spaces definition and (b) emergence of the detailed geometry of the case study.

Based on these, the parts have been designed by following two approaches including the one proposed in this paper and another one based on lattice structures. As an example, Figure $10 \mathrm{~b}$ presents a lattice structure developed for the tail stock (i.e., part 4 in Table 3 ). The design has been made in alignment with the required mechanical behavior of the part as well as the selected technique capabilities. On the other hand, the main body (i.e., part 1 in Table 3) has been defined by using the proposed methodology. The final design results from a flow of integrated design intents, enabling to get an improved solution from a top-down manner.

\section{Conclusions and Future Work}

In a call to action regarding assembly-level DFAM, Yang et al. [11] stated that "the lack of decision-making support for function integration and part consolidation hinders the search for supreme boundary". In this paper, the highlighted gap has been somewhat filled, in that a support tool for part consolidation-based on the specific characteristics of the AM machines available in a factory and the relationships between the parts-has been proposed. 
It is a framework for new product development, with the goal of seizing the assemblyrelated benefits of AM. These include: PC, in situ assembly of moving components, multimaterial printing. It has been shown that seizing these benefits depend on what the available AM machines are actually capable of. A proposal has then been made-based on a set of desired components' characteristics-to select the best AM techniques that allow both for a seamless manufacturing of the product and architecture minimization. Function integration - which has been implicitly covered by part consolidation-could be integrated in the proposed approach by enlarging its scope to conceptual design as suggested in [11]. Considering it has the potential outcome of increasing product performance. Nevertheless, this research has revealed areas of investigation that are worth considering for improving DFAM in general and opportunities for improving our proposal particularly:

- AM materials description. There must be a way to describe materials (be they proprietary or generic) that is consistent with all the existing machines. Some materials may have nearly the same properties, but with quite different names. Some machine manufacturers may call their material with a generic name like ABS, PLA; such names should be made more explicit. Indeed, ABS for an Ultimaker FFF machine may not have the same properties as ABS extruded from a Stratasys FDM (fused deposition modeling) machine.

- Cost as a selection criterion. Criteria such as cost could be included in the preliminary machines selection. Indeed, the approach led to cases where the main selected AM machine and material combination was actually the most expensive one, while there are other available cheaper AM machines that could also seamlessly manufacture the assembly with the prescribed parts' requirements.

- An indicator of viability of AM of assembly. In case many of the components are outsourced, operations such as assembly during AM may dramatically increase the production time. There should therefore be an indicator that quickly checks the architecture and the parts' requirements and tells how valuable it can be to consider the product for AM.

As AM is still in its infancy compared to the conventional manufacturing techniques, it is likely that the full potentials of AM may not be seen in the current generation of designers' artifacts. As such, education is to play a crucial role in allowing the AM paradigm shift completeness [58]. In the proposed approach, machine limitations, especially those related to build space have not been considered in the minimal architecture derivation. However, these can require a product (or even a part) to be digitally cut before AM and reassembled afterwards. A future work could include in the minimum architecture generation of such limitations by considering integration of interlocking features as shown in Song et al. [49].

Author Contributions: Conceptualization, G.S. and F.D.; Methodology, G.S. and F.D.; Writingoriginal draft preparation, G.S.; Writing — review and editing, F.D.; Supervision, S.G. and G.M. All authors have read and agreed to the published version of the manuscript.

Funding: This research was partially funded by the French 'Investissements d'Avenir' program, project ISITE-BFC (contract ANR-15-IDEX-0003), the EIPHI Graduate School (contract ANR-17-EURE0002), the S.mart academic network, and the Bourgogne Franche-Comté Region.

Institutional Review Board Statement: Not applicable.

Informed Consent Statement: Not applicable.

Data Availability Statement: Not applicable.

Conflicts of Interest: The authors declare no conflict of interest. 


\section{Appendix A}

Table A1. Available AM Machines.

\begin{tabular}{|c|c|c|c|c|c|c|c|c|c|c|}
\hline Machine & $\begin{array}{c}\text { AM } \\
\text { Technique }\end{array}$ & $\begin{array}{r}\text { Min Wall } \\
\text { Thickness }\end{array}$ & Accuracy & Surface Finish & $\begin{array}{c}\text { Max } \\
\underset{(\mathrm{mm})}{\text { Dimensions }} \\
\end{array}$ & Material Type & Processed Materials & $\begin{array}{c}\text { Multi- } \\
\text { Material }\end{array}$ & $\begin{array}{l}\text { Capability to } \\
\text { Print } \\
\text { Electronics }\end{array}$ & $\begin{array}{c}\text { Capability to } \\
\text { Build around } \\
\text { Insert }\end{array}$ \\
\hline $\begin{array}{l}\text { Ultimaker } 3 \\
\text { Extended }\end{array}$ & FDM & Very thin & Average & Good-average & $197 \times 215 \times 300$ & Polymers & $\begin{array}{l}\text { Nylon, PLA, ABS, CPE, } \\
\text { CPE+, PVA, PC, TPU 95A, } \\
\text { PP, Breakaway }\end{array}$ & Yes & No & Yes \\
\hline Ultimaker 2+ & FDM & Very thin & Average & Good-average & $223 \times 233 \times 205$ & Polymers & $\begin{array}{l}\text { PLA, ABS, CPE, CPE+, PC, } \\
\text { Nylon, TPU 95A, PP }\end{array}$ & No & No & Yes \\
\hline Objet30 & PolyJet & Very thin & Tight & Excellent & $294 \times 192 \times 149$ & Polymers; Wax & $\begin{array}{l}\text { VeroWhitePlus }{ }^{\mathrm{TM}}, \\
\text { VeroGray }^{\mathrm{TM}}, \text { VeroBlue }^{\mathrm{TM}}, \\
\text { VeroBlack }^{\mathrm{TM}}, \text { Durus }\end{array}$ & Yes & No & No \\
\hline Form 2 & SLA & Very thin & Tight & Excellent & $145 \times 145 \times 175$ & Polymers & $\begin{array}{l}\text { CLEAR FLGPCL03, HIGH } \\
\text { TEMP FLHTAM01, TOUGH } \\
\text { FLTOTL03, DURABLE } \\
\text { FLDUCL01, FLEXIBLE } \\
\text { FLFLGR02, DENTAL SG } \\
\text { FLDGOR01, CASTABLE } \\
\text { FLCABL02 }\end{array}$ & No & No & No \\
\hline EOS P 77 & SLS & Very thin & Tight & Good-average & $700 \times 380 \times 580$ & Polymers & $\begin{array}{l}\text { Alumide, PA 1101, PA 1102 } \\
\text { black, PA 2200, PA 2201, PA } \\
3200 \text { GF, PrimeCast 101, } \\
\text { PrimePart FR (PA 2241 FR), }\end{array}$ & No & No & No \\
\hline FORMIGA P 110 & SLS & Very thin & Tight & Good-average & $200 \times 250 \times 330$ & Polymers & $\begin{array}{l}\text { PA 2200, PA 2201, PA } 3200 \\
\text { GF, PrimeCast 101, PA } 2105\end{array}$ & No & No & No \\
\hline
\end{tabular}




\section{References}

1. Kuo, T.-C.; Huang, S.H.; Zhang, H.-C. Design for manufacture and design for ' $\mathrm{x}$ ': Concepts, applications, and perspectives. Comput. Ind. Eng. 2001, 41, 241-260. [CrossRef]

2. Demoly, F.; Yan, X.-T.; Eynard, B.; Rivest, L.; Gomes, S. An assembly oriented design framework for product structure engineering and assembly sequence planning. Robot. Comput. Integr. Manuf. 2011, 27, 33-46. [CrossRef]

3. Gao, W.; Zhang, Y.; Ramanujan, D.; Ramani, K.; Chen, Y.; Williams, C.B.; Wang, C.C.L.; Shin, Y.C.; Zhang, S.; Zavattieri, P.D. The status, challenges, and future of additive manufacturing in engineering. Comput. Aided Des. 2015, 69, 65-89. [CrossRef]

4. Thompson, M.K.; Moroni, G.; Vaneker, T.; Fadel, G.; Campbell, R.I.; Gibson, I.; Bernard, A.; Schulz, J.; Graf, P.; Ahuja, B.; et al Design for additive manufacturing: Trends, opportunities, considerations, and constraints. CIRP Ann. Manuf. Technol. 2016, 65, 737-760. [CrossRef]

5. Pradel, P.; Zhu, Z.; Bibb, R.; Moultrie, J. Investigation of design for additive manufacturing in professional design practice. J. Eng. Des. 2018, 29, 165-200. [CrossRef]

6. $\quad$ Pradel, P.; Zhu, Z.; Bibb, R.; Moultrie, J. A framework for mapping design for additive manufacturing knowledge for industrial and product design. J. Eng. Des. 2018, 29, 291-326. [CrossRef]

7. Fillingim, K.B.; Nwaeri, R.O.; Paredis, C.J.J.; Rosen, D.; Fu, K. Examining the effect of design for additive manufacturing rule presentation on part redesign quality. J. Eng. Des. 2020, 31, 427-460. [CrossRef]

8. Becker, R.; Grzesiak, A.; Henning, A. Rethink assembly design. Assem. Autom. 2005, 25, 262-266. [CrossRef]

9. Bin Maidin, S.; Campbell, I.; Pei, E. Development of a design feature database to support design for additive manufacturing. Assem. Autom. 2012, 32, 235-244. [CrossRef]

10. Laverne, F.; Segonds, F.; Anwer, N.; Le Coq, M. Assembly based methods to support product innovation in design for additive manufacturing: An exploratory case study. J. Mech. Des. 2015, 137, 121701. [CrossRef]

11. Yang, S.; Zhao, Y.F. Conceptual design for assembly in the context of additive manufacturing. In Proceedings of the 2016 Annual International Solid Freeform Fabrication Symposium, Austin, TX, USA, 8-10 August 2016.

12. Mokhtarian, H.; Coatanéa, E.; Paris, H.; Mbow, M.M.; Pourroy, F.; Marin, P.R.; Vihinen, J.; Ellman, A. A conceptual design and modeling framework for integrated additive manufacturing. J. Mech. Des. 2018, 140, 081101. [CrossRef]

13. Orquéra, M.; Campocasso, S.; Millet, D. Some principles to optimise an additively manufactured multi-component product. $J$ Eng. Des. 2019, 31, 219-240. [CrossRef]

14. Cuellar, J.S.; Smit, G.; Plettenburg, D.; Zadpoor, A. Additive manufacturing of non-assembly mechanisms. Addit. Manuf. 2018, 21, 150-158. [CrossRef]

15. Lebaal, N.; Zhang, Y.; Demoly, F.; Roth, S.; Gomes, S.; Bernard, A. Optimised lattice structure configuration for additive manufacturing. CIRP Ann. Manuf. Technol. 2019, 6, 117-120. [CrossRef]

16. Al Khalil, M.; Lebaal, N.; Demoly, F.; Roth, S. A design and optimization framework of variable-density lattice structures for additive manufacturing. Mech. Adv. Mater. Struct. 2021, 1-15. [CrossRef]

17. Hague, R. Unlocking the Design Potential of Rapid Manufacturing; John Wiley \& Sons, Ltd.: Hoboken, NJ, USA, 2006.

18. Schmelzle, J.; Kline, E.V.; Dickman, C.J.; Reutzel, E.W.; Jones, G.; Simpson, T.W. (Re)Designing for part consolidation: Understanding the challenges of metal additive manufacturing. J. Mech. Des. 2015, 137, 111404. [CrossRef]

19. Yang, S.; Tang, Y.; Zhao, Y.F. A new part consolidation method to embrace the design freedom of additive manufacturing. $J$. Manuf. Process. 2015, 20 Pt 3, 444-449. [CrossRef]

20. Rodrigue, H.; Rivette, M. An assembly-level design for additive manufacturing methodology. In Proceedings of the IDMMEVirtual Concept, Bordeaux, France, 20-22 October 2010.

21. Boothroyd, G.; Dewhurst, P. Product Design for Assembly; Boothroyd Dewhurst, Inc.: Wakefield, RI, USA, 1990.

22. Yang, S.; Zhao, Y.F. Additive manufacturing-enabled part count reduction: A lifecycle perspective. J. Mech. Des. 2018, 140, 031702. [CrossRef]

23. Kellner, T. The FAA Cleared the First 3D Printed Part to Fly in a Commercial Jet Engine from GE; General Electric: Boston, MA, USA, 2015

24. Rias, A.-L.; Bouchard, C.; Segonds, F.; Abed, S. Design for additive manufacturing: A creative approach. In Proceedings of the 14th International Design Conference, Dubrovnik, Croatia, 16-19 May 2016.

25. Yang, S.; Santoro, F.; Zhao, Y.F. Towards a numerical approach of finding candidates for additive manufacturing-enabled part consolidation. J. Mech. Des. 2018, 140, 041701. [CrossRef]

26. Yang, S.; Tang, Y.; Zhao, Y.F. Assembly-level design for additive manufacturing: Issues and benchmark. In Proceedings of the ASME 2016 International Design Engineering Technical Conferences and Computers and Information in Engineering Conference, Charlotte, NC, USA, 21-24 August 2016.

27. Gibson, I.; Rosen, D.W.; Stucker, B. Additive Manufacturing Technologies: Rapid Prototyping to Direct Digital Manufacturing, 1st ed.; Springer Publishing Company Incorporated: Berlin/Heidelberg, Germany, 2009.

28. Vaezi, M.; Chianrabutra, S.; Mellor, B.; Yang, S. Multiple material additive manufacturing_Part 1: A review. Virtual Phys. Prototyp. 2013, 8, 19-50. [CrossRef]

29. Wilson, J.M.; Shin, Y.C. Microstructure and wear properties of laser-deposited functionally graded inconel 690 reinforced with tic Surf. Coat. Technol. 2012, 207, 517-522. [CrossRef] 
30. Bandyopadhyay, A.; Krishna, B.V.; Xue, W.; Bose, S. Application of laser engineered net shaping (lens) to manufacture porous and functionally graded structures for load bearing implants. J. Mater. Sci. Mater. Med. 2009, 20, 29-34. [CrossRef] [PubMed]

31. Garland, A.; Fadel, G. Design and manufacturing functionally gradient material objects with an off the shelf three-dimensional printer: Challenges and solutions. J. Mech. Des. 2015, 137, 11140. [CrossRef]

32. Lipson, H.; Moon, F.C.; Hai, J.; Paventi, C. 3-d printing the history of mechanisms. J. Mech. Des. 2004, 127, 1029-1033. [CrossRef]

33. Kataria, A.; Rosen, D.W. Building around inserts: Methods for fabricating complex devices in stereolithography. Rapid Prototyp. J. 2001, 7, 253-262. [CrossRef]

34. White, D. Ultrasonic consolidation of aluminum tooling. Adv. Mater. Processes 2003, 161, $64-65$.

35. Liao, Y.S.; Li, H.C.; Chen, M.T. The study of rapid prototyping process with embedded functional inserts. J. Mater. Process. Technol. 2007, 192-193, 68-74. [CrossRef]

36. Merz, R.; Prinz, F.; Ramaswami, K.; Terk, M.; Weiss, L. Shape deposition manufacturing. In Proceedings of the International Solid Freeform Fabrication Symposium, Austin, TX, USA, 8-10 August 1994.

37. Meisel, N.A.; Elliott, A.M.; Williams, C.B. A procedure for creating actuated joints via embedding shape memory alloys in polyjet 3d printing. J. Intell. Mater. Syst. Struct. 2014, 26, 1498-1512. [CrossRef]

38. Molitch-Hou, M. The World's First 3D Electronics Printer. Available online: https://3dprintingindustry.com/news/voxel8 -unleashes-electronics-3d-printer-ces-world-39060/ (accessed on 15 January 2022).

39. Calì, J.; Calian, D.A.; Amati, C.; Kleinberger, R.; Steed, A.; Kautz, J.; Weyrich, T. 3D-printing of non-assembly, articulated models. ACM Trans. Graph. 2012, 31, 1-8. [CrossRef]

40. Mavroidis, C.; Delaurentis, K.J.; Won, J.; Alam, M. Fabrication of non-assembly mechanisms and robotic systems using rapid prototyping. J. Mech. Des. 2000, 123, 516-524. [CrossRef]

41. Song, X.; Chen, Y. Joint design for 3-d printing non-assembly mechanisms. In Proceedings of the ASME International Design Engineering Technical Conferences and Computers and Information in Engineering Conference, Chicago, IL, USA, 12-15 August 2012; pp. 619-631.

42. Stöckli, F.; Modica, F.; Shea, K. Designing passive dynamic walking robots for additive manufacture. Rapid Prototyp. J. 2016, 22, 842-847. [CrossRef]

43. Wei, X.; Tian, Y.; Joneja, A. A study on revolute joints in 3d-printed non-assembly mechanisms. Rapid Prototyp. J. 2016, 22, 901-933. [CrossRef]

44. Calignano, F.; Manfredi, D.; Ambrosio, E.P.; Biamino, S.; Pavese, M.; Fino, P. Direct fabrication of joints based on direct metal laser sintering in aluminum and titanium alloys. Procedia CIRP 2014, 21, 129-132. [CrossRef]

45. Song, C.H.; Yang, Y.Q.; Xiao, Z.F.; Wang, D.; Liu, Y.; Liu, R.C. Design and direct manufacture of non-assembly abacus by selective laser melting. In International Symposium on Optoelectronic Technology and Application 2014: Laser Materials Processing and Micro/Nano Technologies; Kaiser, N., Li, B., Ji, Y., Verhaeghe, G., Zhong, M., Lu, B., Wang, H., Leu, M.C., Yan, Y., Xie, H., et al., Eds.; SPIE-International Society for Optical Engineering: Bellingham, WA, USA, 2014.

46. Su, X.; Yang, Y.; Wang, D.; Chen, Y. 2013. Digital assembly and direct fabrication of mechanism based on selective laser melting. Rapid Prototyp. J. 2013, 19, 166-172. [CrossRef]

47. Chen, Y.; Zhezheng, C. Joint analysis in rapid fabrication of non-assembly mechanisms. Rapid Prototyp. J. 2011, 17, 408-417. [CrossRef]

48. Wei, Y.; Chen, Y.H.; Yang, Y.; Li, Y.T. Novel design and 3-D printing of nonassembly controllable pneumatic robots. IEEE/ASME Trans. Mechatron. 2016, 21, 649-659. [CrossRef]

49. Song, P.; Fu, Z.; Liu, L.; Fu, C.-W. Printing 3D objects with interlocking parts. Comput. Aided Geom. Des. 2015, 35-36, 137-148. [CrossRef]

50. Kerbrat, O.; Mognol, P.; Hascoët, J.Y. A new DFM approach to combine machining and additive manufacturing. Comput. Ind. 2011, 62, 684-692. [CrossRef]

51. Hirtz, J.; Stone, R.B.; McAdams, D.A.; Szykman, S.; Wood, K.L. A functional basis for engineering design: Reconciling and evolving previous efforts. Res. Eng. Des. 2022, 13, 65-82. [CrossRef]

52. Demoly, F.; Matsokis, A.; Kiritsis, D. A mereotopological product relationship description approach for assembly oriented design. Robot. Comput. Integr. Manuf. 2012, 28, 681-693. [CrossRef]

53. Ghazy, M.M.S.A. Development of an Additive Manufacturing Decision Support System (AMDSS). Ph.D. Thesis, University of Newcastle upon Tyne, Newcastle upon Tyne, UK, 2012.

54. Wang, Y.; Blache, R.; Xu, X. Selection of additive manufacturing processes. Rapid Prototyp. J. 2017, 23, 434-447. [CrossRef]

55. Sossou, G.; Demoly, F.; Montavon, G.; Gomes, S. An additive manufacturing oriented design approach to mechanical assemblies. J. Comput. Des. Eng. 2018, 5, 3-18. [CrossRef]

56. Pahl, G.; Beitz, W.; Feldhusen, J.; Grote, K.H. Engineering Design: A Systematic Approach, 3rd ed.; Springer London Ltd.: London, $\mathrm{UK}, 2007$.

57. Ullman, D. The Mechanical Design Process, 4th ed.; McGraw-Hill Education: New York, NY, USA, 2009.

58. Williams, C.; Seepersad, C.C. Design for Additive Manufacturing Curriculum: A Problem- and Project-Based Approach. In Proceedings of the Solid Freeform Fabrication Symposium, Austin, TX, USA, 6-8 August 2012. 